A R T Í C U L O

\title{
UNA ATLÁNTIDA EN EL GOLFO ÁRTABRO: LA ARQUITECTURA DE LOS ASTILLEROS Y TALLERES DEL NOROESTE ENTRE 1954 Y 1962
}

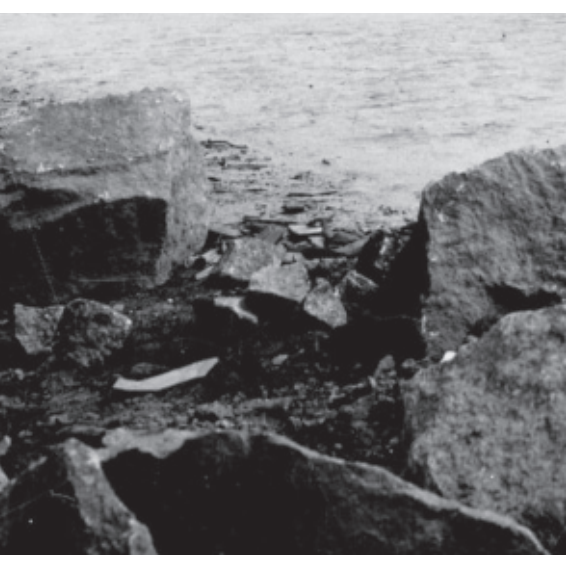

\author{
Antonio S. Río Vázquez
}

An Atlantis in the Artabrian gulf: the architecture of Astilleros $y$ Talleres del Noroeste between 1954 and 1962

Boletín Académico. Revista de investigación y arquitectura contemporánea

Escuela Técnica Superior de Arquitectura. Universidade da Coruña

elSSN 2173-6723

unw.boletinacademico.com

Número 4 (2014)

Páginas 63-70

Fecha de recepción 30.10.2013

Fecha de aceptación 22.01.2014

https://doi.org/10.17979/bac.2014.4.0.1010

\section{Resumen}

Entre 1954 y 1962, la empresa Astilleros y Talleres del Noroeste (Astano), situada en la ría de Ferrol, pasa de ser un pequeño astillero de ribera a convertirse en una referencia en el mercado mundial. Durante ese período, se fue levantando un conjunto de instalaciones para albergar las distintas fases del proceso de construcción naval, atendiendo a una clara organización funcional, buscando un espacio de trabajo luminoso y optimizado, y empleando las soluciones constructivas más avanzadas del momento. El resultado se puede entender hoy como un ejemplo de la recuperación de la modernidad en la arquitectura gallega del siglo XX.

\begin{abstract}
Between 1954 and 1962, the company Astilleros y Talleres del Noroeste (Astano), located in the Ria de Ferrol, goes from being a small bank shipyard to become a reference in the world market. During that period they were lifting a set of facilities to house the different phases of the shipbuilding process, based on a clear functional organization, looking for a bright and optimized workspace and using the most advanced construction techniques. The result can be understood today as an example of the recovery of modernity in twentieth-century Galician architecture.
\end{abstract}

\section{Palabras clave}

Astano, Arquitectura, Siglo XX, Galicia, España

\section{Keywords}

Astano, Architecture, Twentieth century, Galicia, Spain 


\section{LOS ORÍGENES DE ASTANO}

Desde 1941 y durante los primeros años de su historia, Astilleros y Talleres del Noroeste (Astano) fue una pequeña empresa ubicada en la ría de Ferrol dedicada a la construcción de pesqueros de madera. Sus instalaciones se reducían a unos talleres de carpintería dónde se desarrollaban las diferentes fases de elaboración y reparación de los barcos (Fig. 01). Sin embargo, su trayectoria en las décadas siguientes cambia completamente, singularizándose entre otros astilleros del momento, tanto en los encargos realizados como en la necesaria modernización de las instalaciones para acometer los nuevos trabajos.

A partir de la Ley de Crédito Naval de 1941 y principalmente, de la Ley de la Protección de la Construcción Naval de 1951, la expansión de los astilleros se vio favorecida por una serie de medidas de apoyo en forma de créditos y subvenciones. Estas aportaciones fomentaron la construcción de embarcaciones con destino a la pesca de altura, al tiempo que favorecieron la capitalización suficiente como para poder dedicarse, ya en la década de los sesenta, a la realización de buques de gran tamaño, incluyendo petroleros.

De modo paralelo al desarrollo de los astilleros, se fue levantando un amplio conjunto de instalaciones que permitiesen albergar las distintas etapas del proceso de construcción naval (Fig. 02). Estas instalaciones se hacen atendiendo a una clara organización funcional, buscando un espacio de trabajo moderno y optimizado. En ellas se emplean -al igual que en los barcos que se producen - las soluciones técnicas más avanzadas del momento. Su arquitectura, apenas estudiada hasta el momento, se convierte en uno de los mejores ejemplos de la recuperación de la modernidad en Galicia, una vez superada la autarquía posterior a la Guerra Civil ${ }^{1}$.

\section{LA MODERNIZACIÓN INDUSTRIAL}

El origen de las transformaciones que tienen lugar en Astano se debe, inicialmente, a las condiciones geográficas que posee la ría de Ferrol, adecuadas para la ubicación de astilleros, con una disponibilidad real y potencial de suelo. $\mathrm{Y}$ al mismo tiempo, bajo la influencia de una villa intensamente marinera, industrial, militar y burguesa, con una rica tradición histórica de construcción naval que se remonta al siglo XVIII, cuando se construyeron las naves para modernizar la flota de los Borbones.
La Ley para la Reconstrucción de la Marina Mercante de junio de 1939 supone un empuje fundamental —iniciado de modo inmediato al final de Guerra Civil- para la creación de nuevos astilleros. Entre ellos se incluye Astano, constituido como sociedad limitada en octubre de 1941 por dieciséis socios encabezados por el ingeniero naval José María González-Llanos y Caruncho $^{2}$, a partir de la compra de los talleres de ribera de Ramón Aguilar Pérez ${ }^{3}$.

El impulso de modernización durante los años cuarenta viene determinado, en gran medida, por la inyección de capital por parte de Industrias Gallegas S.A., perteneciente al holding del Banco Pastor, lo que permite convertir la sociedad limitada en una sociedad anónima, incorporar al Instituto Nacional de Industria como accionista mayoritario de la empresa, y acometer la necesaria transformación de las instalaciones para los nuevos encargos.

Para realizar esta metamorfosis empresarial y arquitectónica, Astano hace uso de sus propios recursos y tradición constructiva: encargándose los ingenieros de la empresa del diseño de los nuevos edificios, empleando las técnicas experimentadas en sucesivos años de construcción naval, y apoyándose en el amplio conocimiento de los espacios necesarios para el proceso de fabricación de los buques.

En el año 1953 se inician las obras, preparando el terreno para la ampliación en el borde sur de la ría de Ferrol. Se trata de zonas totalmente ganadas al mar, lo que implica el uso de un complejo sistema de pilotes hincados para soportar tanto la estructura de los talleres como los pesos muertos de los buques en construcción.

\section{CONSTRUYENDO UNA ATLÁNTIDA DE HORMIGÓN}

Los espacios de carácter industrial constituyen un tipo particular de desafío: producir con éxito una arquitectura fabril económica y de calidad, que sea flexible y práctica para albergar los procesos industriales y que configure al mismo tiempo un entorno favorable para los trabajadores, requiere una amplia experiencia y pericia ${ }^{4}$. Los astilleros demandaban espacios cubiertos de grandes dimensiones, que permitieran realizar las actividades de una manera confortable y ambientalmente controlada, por lo que se proyecta una piel modulada y homogénea, un tamiz de luz que se convierte en la fachada tipo para los edificios industriales. 


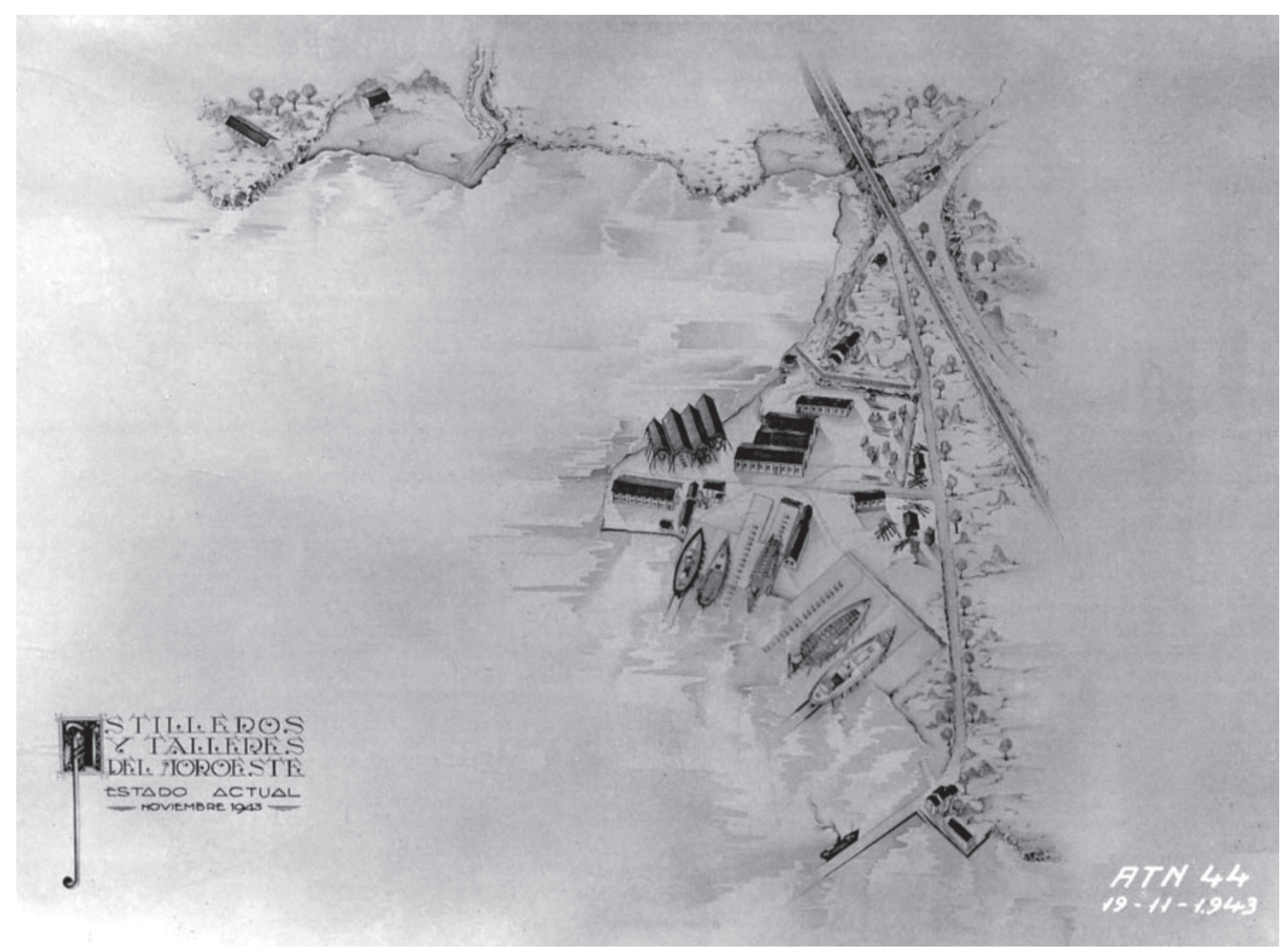

01 Astano. Vista general de los astilleros en noviembre de 1943.

02 Planta general de los astilleros en 1962.

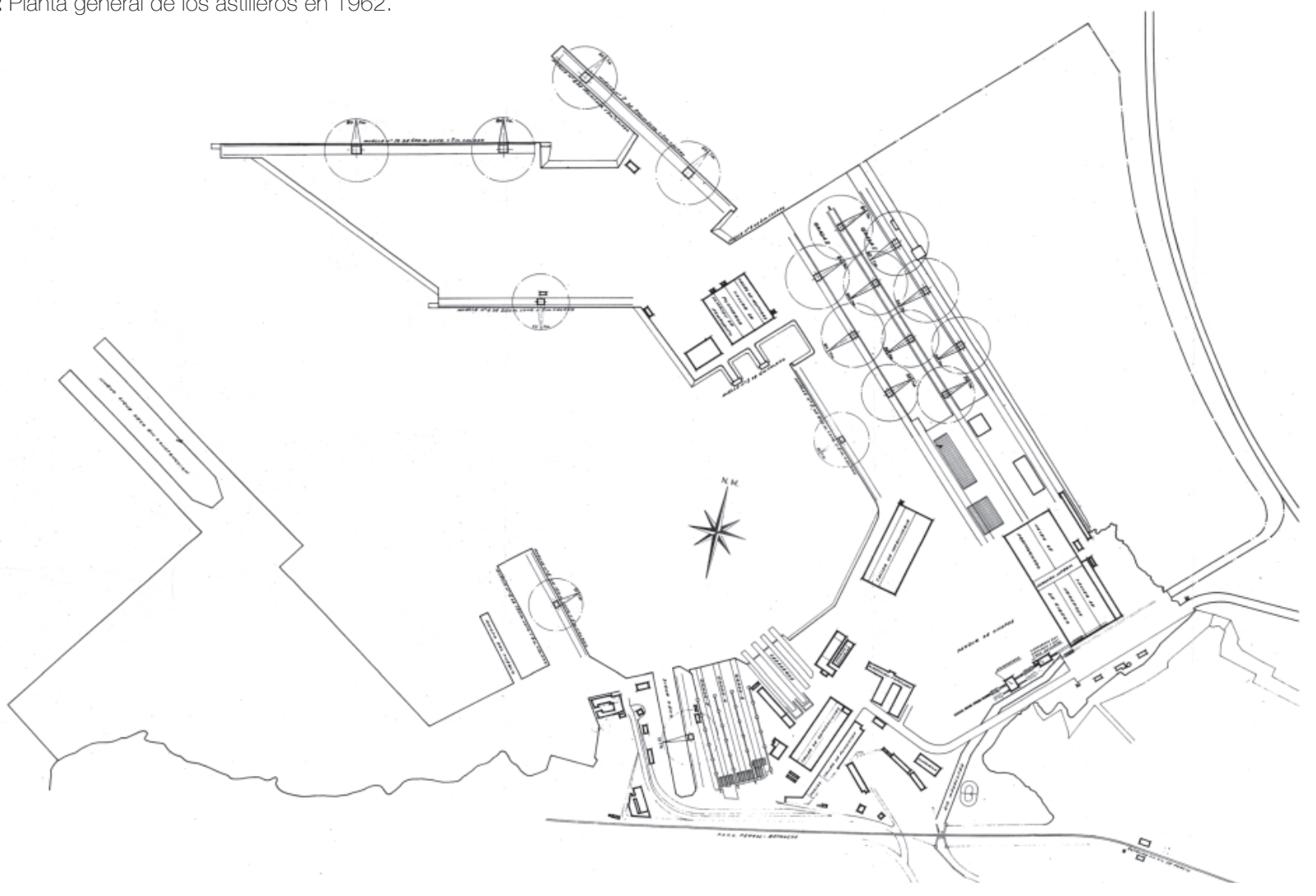




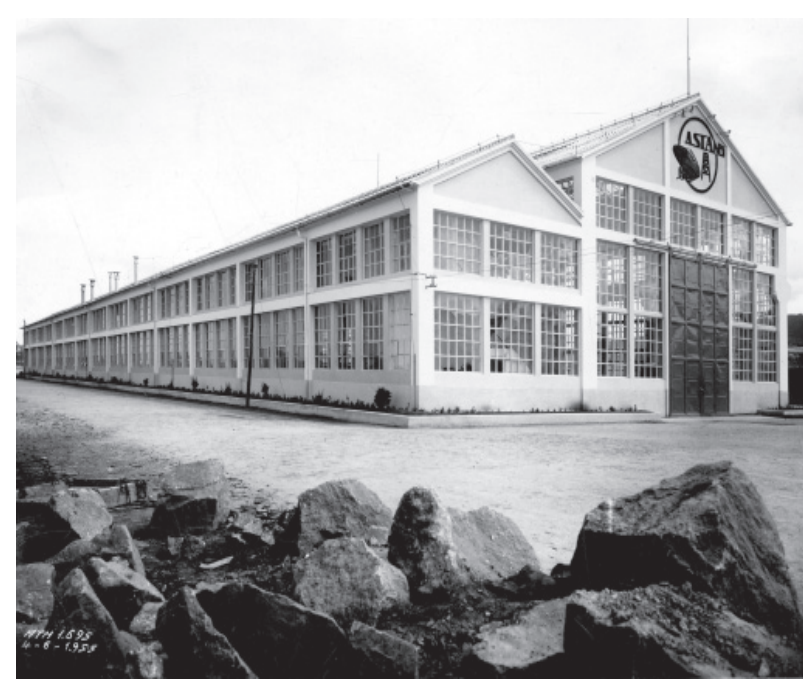

03 Taller de Maquinaria (1954).

04 Edificio de Oficinas Generales (1955).

En 1954 se construyen las naves del Taller de Maquinaria (Fig. 03), con dos largas crujías paralelas al muelle y un cerramiento totalmente acristalado. Las dos comparten la modulación estructural, aunque la nave principal posee el doble de altura que la secundaria. Inicialmente proyectadas con estructura de acero, la dificultad del momento para conseguir este material y su alto coste — debido al cierre de los mercados internacionales por la Segunda Guerra Mundial y a una escasa producción nacional-, conduce a su realización en hormigón armado, empleándose este material para los pilares, las cerchas e incluso las carpinterías de las naves: "Los ventanales de la fachada, así como la coronación de los tabiques interiores de la planta baja, que forman como un montante corrido, entre la viga horizontal de la entreplanta y el zócalo macizo interior de 1,6 metros de altura, se construyen, todas, prefabricadas de hormigón armado, lo que hará el conjunto de los paramentos así construidos, tanto o más económicos, que si fuesen macizos, dado el gran ahorro en materiales y, sobre todo, en mano de obra».

La concepción y justificación constructiva es documentada con claridad y exhaustividad en los proyectos, explicando las razones de la elección de cada material y sistema y aportando gran cantidad de información gráfica, mucha más que para la construcción edilicia del momento, demostrando cómo la precisión y la racionalidad de la construcción naval se quiere trasladar a la arquitectura ${ }^{6}$. Ese planteamiento enlaza perfectamente con los principios defendidos por los arquitectos de la recuperación moderna: la autoformación, la optimización de técnicas y recursos, los traba-

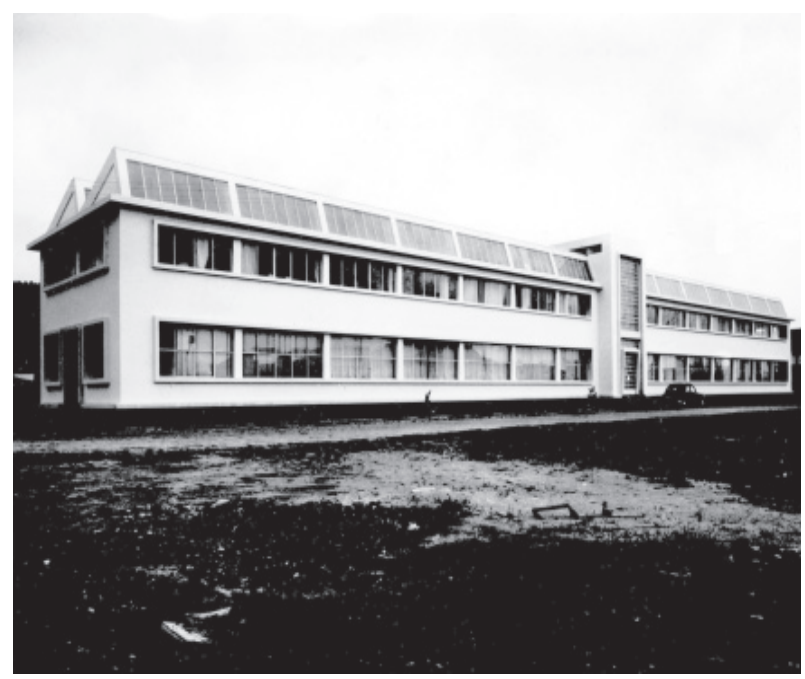

jos interdisciplinares y en equipo... son aspectos que se desarrollan y consolidan durante esos años y que aquí aparecen de modo paradigmático.

La documentación recoge también el interés por generar sus propios elementos constructivos, haciendo un uso ampliado de la fabricación de piezas para barcos. Así, dentro de los astilleros se diseñan y fabrican las grandes puertas correderas, tiradores o barandillas, abarcando todas las escalas de trabajo de la arquitectura moderna: desde el objeto hasta la implantación urbana.

En 1955 se realiza el Edificio de Oficinas Generales (Fig. 04), un volumen puro de líneas racionalistas organizado a través de un núcleo de distribución central, con una escalera de caracol que se asoma hacia el exterior y se corona con una vidriera alusiva al trabajo realizado en los astilleros. Para singularizar la cabeza rectora, se emplea una arquitectura diferenciada, descartando la fachada tipo del resto de los edificios y optando por una composición clásica que le otorga un carácter noble y singular dentro del conjunto.

A mediados de los cincuenta, coincidiendo con la entrada en vigor de la Ley de Protección y Renovación de la Flota Mercante (1956) y el apoyo por parte del gobierno tecnócrata a la industria en general, otro hecho externo supone un empujón inesperado al desarrollo empresarial de Astano: la nacionalización por parte del presidente egipcio Gamal Abdel Nasser del Canal de Suez (julio de 1956), obligando a las principales compañías petrolíferas a dotarse de grandes buques a los que resultará rentable bordear el continente africano para evitar los nuevos peajes. 
-

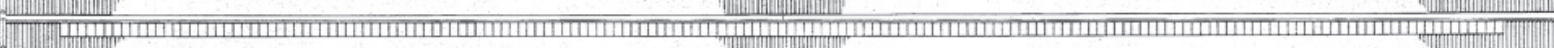

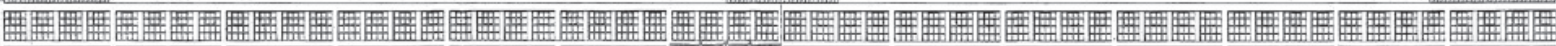

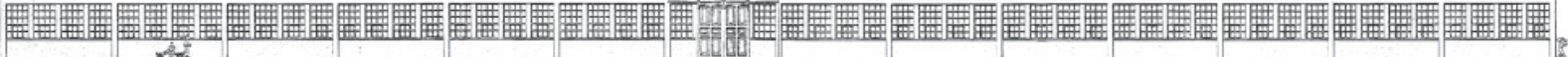

LZAOe mave SaYA

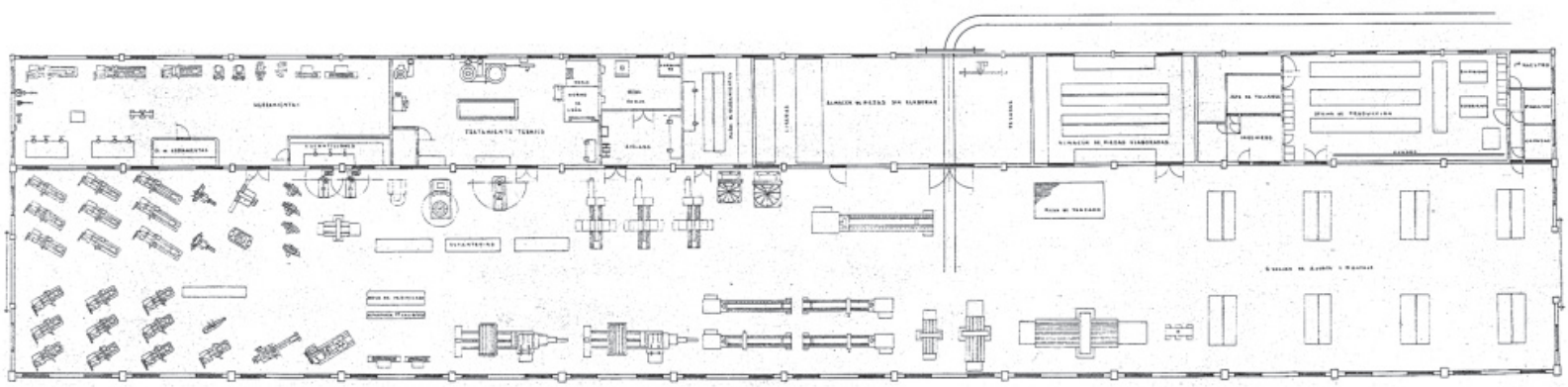

05 Planta y alzado lateral del Taller de Maquinaria y su ampliación (1957).

06 Ampliación del Taller de Maquinaria (1957).

07 Taller de Herreros de Ribera (1957).
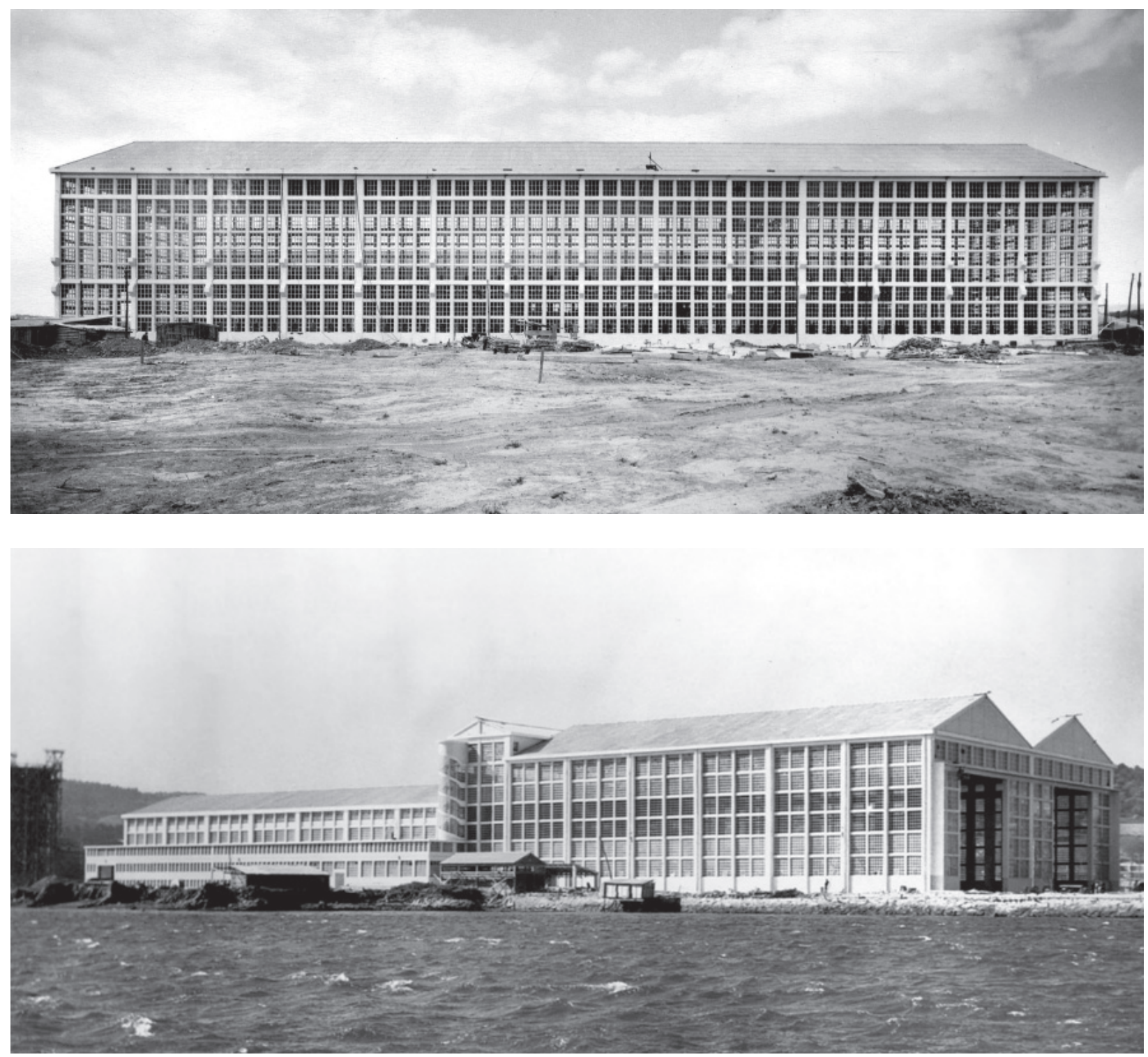

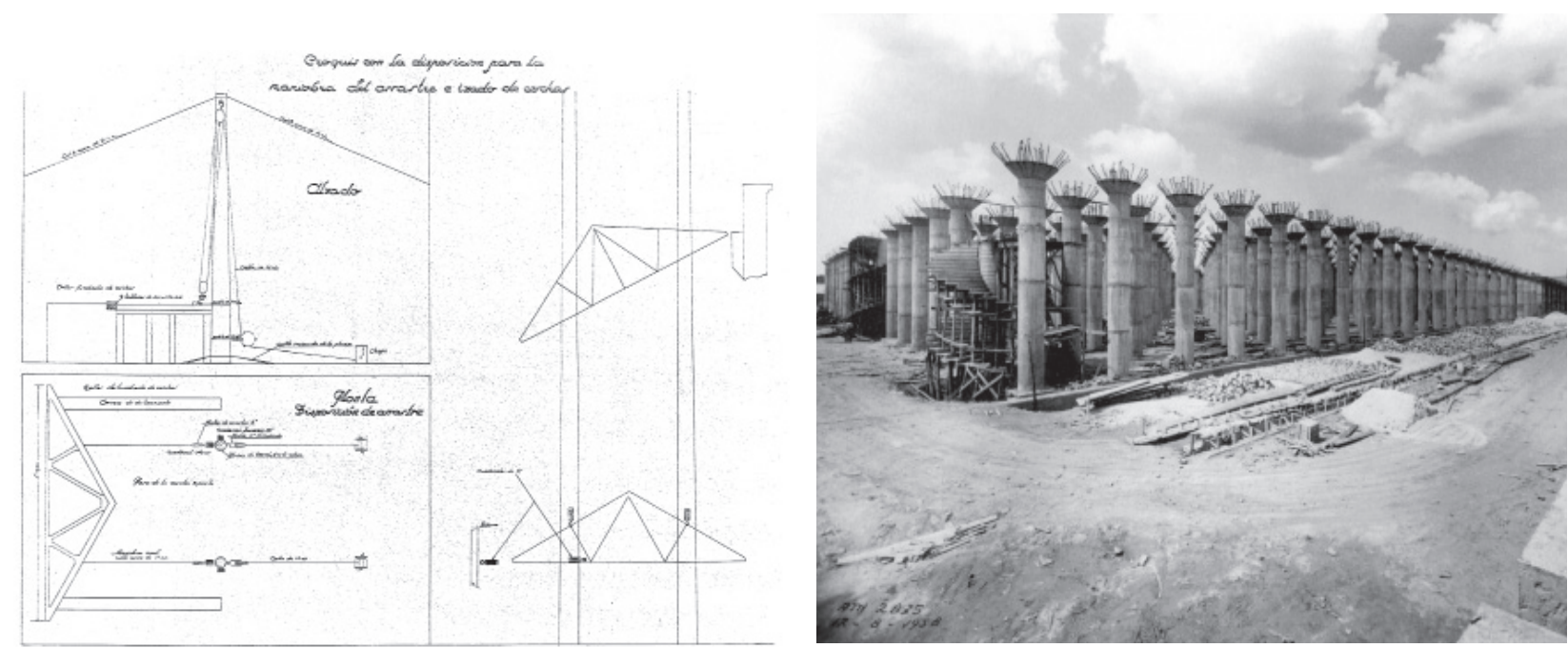

08 Croquis con la disposición para la maniobra del arrastre e izado de las cerchas en los talleres (1957). 09 Gradas I y II (1957).

En 1957 se construye la ampliación del Taller de Maquinaria (Fig. 05 y 06), adosada al existente y manteniendo el lenguaje empleado: una prístina caja de luz con un puente grúa que se desplaza a través de su interior y se duplica hacia el exterior de la nave, ofreciendo un espacio adicional dónde desarrollar las operaciones de montaje.

Paralelamente se construye el Taller de Herreros de Ribera (Fig. 07), la pieza más grande de este periodo, optimizando las soluciones planteadas en los Talleres de Maquinaria con una superficie cubierta mayor que supera los $10.000 \mathrm{~m}^{2}$. Se mantiene la rígida modulación de la piel de vidrio y hormigón pero se opta por una planta próxima a la cruz latina, dónde la secuencia de naves paralelas es interrumpida por un transepto que, al llegar a su extremo este se destaca con una escalera de caracol acristalada.

Observando los elementos accesorios de estos talleres, como los peldaños o las barandillas, sorprende la pureza, sencillez y cuidado detalle con el que se resuelven. Se traslada a la arquitectura los principios de la construcción naval, eliminando aquello que es superfluo y dejando sólo lo necesario; pervive la belleza como resplandor de la verdad, recuperando principios básicos de la modernidad arquitectónica (Fig. 08).

Estas instalaciones fabriles se convierten en auténticas catedrales para el trabajo, con largas naves acristaladas y la salida de los buques hacia las gradas en el lugar que ocuparía la cabecera del templo. Junto a esas catedrales, las gradas I y II, de 40 metros de manga y 160 metros de fondo (Fig. 09), construidas también en 1957, configuran una moderna y monumental sala hipóstila haciendo de todo el conjunto edificado una luminosa y ordenada Atlántida de hormigón, recordando a la descrita en los Estados Unidos por Reyner Banham: «Sin embargo, se trataba de una estructura del mismo tipo y generación que las que Le Corbusier había utilizado para ejemplificar sus argumentos: edificios industriales americanos de varios pisos con un armazón de hormigón al descubierto, relleno de vidrieras transparentes. Edificios como imágenes de rayos $\mathrm{X}$, con los huesos a la vista del público»?

Ejemplo perfecto de esta moderna Atlántida son las cuatro naves de los Talleres de Monturas y Tuberos (1958), situadas próximas y paralelas a las gradas y resueltas con una estricta retícula de $4 \times 9$ módulos estructurales (Fig. 10 ), que se hacen volumen empleando las mismas herramientas que el resto de instalaciones, logrando una gran unidad en todo el conjunto edificado.

La arquitectura de Astano es la arquitectura de los ingenieros, construida con la técnica de su tiempo. Lo había anticipado Le Corbusier: «Simplemente guiados por las necesidades de un programa imperativo, los ingenieros de nuestros días recurren a las generatrices acusadoras de los volúmenes; muestran el camino y crean realidades plásticas, claras y límpidas, brindando paz a los ojos, y los goces de la geometría al espíritu. Así son las fábricas, tranquilizadoras primicias del tiempo nuevo» ${ }^{8}$.

\section{LAS TRANSFORMACIONES TERRITORIALES}

Con el primer Plan de Desarrollo Económico y Social del año 1964, la industria naval española consigue las mayores cifras hasta el momento, y la empresa ártabra aumenta no- 


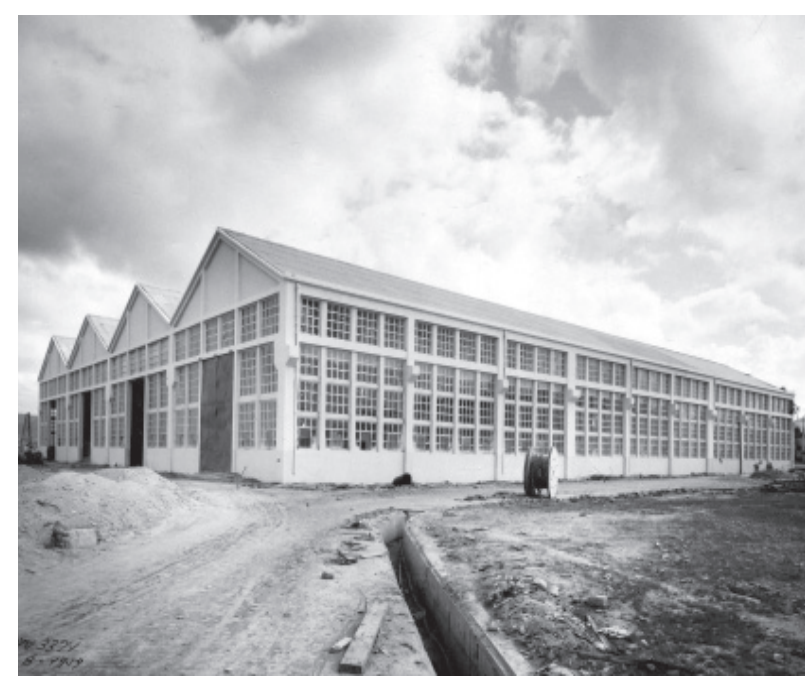

10 Taller de Monturas y Tuberos (1958).

11 Cooperativa de viviendas San Valentín y grúa-pórtico (1970).

tablementesu capacidad de producción, con la ampliación de las gradas y la compra de varias grúas que se convierten en los hitos reconocibles del paisaje artificial de la ribera.

A finales de los años sesenta, Astano se especializa en la construcción de grandes buques y, con el segundo Plan de Desarrollo (1968/71), se levanta el icono fabril por excelencia de la comarca: la colosal grúapórtico de 145 metros de luz y 87 de altura, auténtico menhir de la modernidad industrial gallega.

El desarrollo experimentado por los astilleros durante esos años hace que la empresa se plantee la necesidad de promover conjuntos de viviendas en las proximidades que permitan alojar a los trabajadores y a sus familias. A las transformaciones industriales se suman las urbanísticas en todo el borde de la ría, haciéndolo artificial y moderno al mismo tiempo.

A finales de los sesenta se produce el desvío y canalización del río Magalofes, que atravesaba los terrenos del astillero, y en el año 1970, se termina la primera etapa de la Cooperativa de Viviendas San Valentín, proyectada por el arquitecto Ramón Tenreiro Brochón (A Coruña, 1928 t. 1957). El nuevo barrio residencial se construye sobre la Chousa de Perlío, en una zona propiedad del astillero, y su dimensión hace que se perciba como una auténtica ciudad en continuidad con las instalaciones industriales (Fig. 11).

Las obras de los bloques comienzan en noviembre de 1962. Durante un tiempo, las estructuras de hormigón en construcción conviven con las estructuras

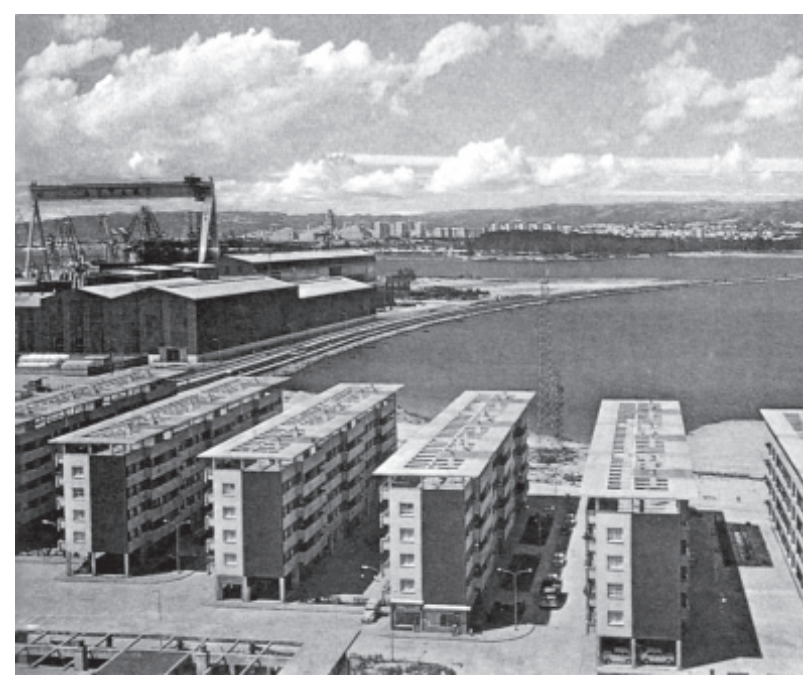

de los grandes buques que se arman en el astillero, mientras que los espacios de las viviendas se diseñan con la misma metodología y lenguaje moderno que se emplea en los camarotes de los barcos. Esa precisión lograda en el hábitat temporal se traslada a el hábitat diario, acompańado de otros preceptos propios de la vivienda moderna: la calculada separación entre bloques para conseguir el correcto soleamiento, las plantas bajas diáfanas - en origen - y una cubierta-jardín coronada por una fina lámina de hormigón que enfatiza la horizontalidad de las piezas.

Las tipologías empleadas se toman también de la urbanística del Movimiento Moderno: bloques lineales en la primera fase y torres en la segunda, que se completan con los elementos singulares propios de la escala de barrio: escuela, capilla, zonas de esparcimiento y otros equipamientos comunitarios.

Los años setenta suponen los primeros recesos para la empresa. Los hitos mundiales en las botaduras de los petroleros Arteaga (1972) y, especialmente, el Santa María (1975), certifican un éxito profesional que no va parejo al éxito económico. A pesar de los importantes logros alcanzados, la crisis del petróleo que estalla en esa década hace desaparecer los encargos de grandes unidades. Desde entonces, Astano afronta una dura y amplia reconversión con un alto coste social para la comarca.

\section{CONCLUSIONES}

La arquitectura proyectada por y para Astano entre 1954 y 1962 nos ha servido para explicar la evolución 


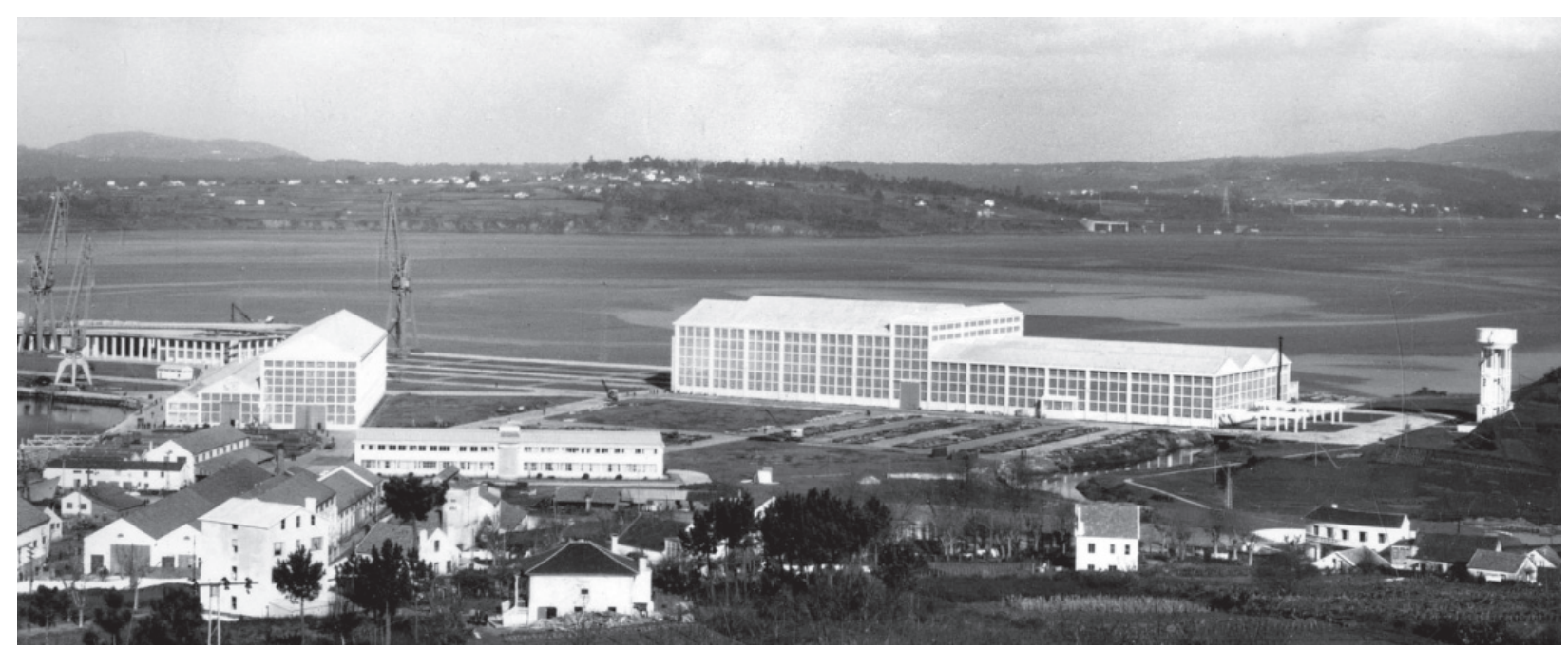

12 Vista general de los astilleros en 1965.

del edificio industrial gracias a la utilización de los materiales y técnicas modernas, pero, sobre todo, gracias a la introducción de una nueva espacialidad. La configuración funcional de los diferentes talleres, su detallada definición constructiva a través del proyecto y la relación con los procesos de fabricación naval son hechos que ponen de manifiesto la recuperación de los principios modernos en la arquitectura industrial del momento.

El territorio del proyecto moderno, desde el objeto a la ciudad, queda patente en la arquitectura de los astilleros (Fig. 12). El diseño de los elementos constructivos o el uso extensivo de las piezas para los barcos se cuida al mismo nivel que el urbanismo de los barrios para trabajadores. La precisión y racionalidad constructiva a todas las escalas se percibe recorriendo todavía hoy las instalaciones, magníficamente conservadas por la empresa Navantia?.

La arquitectura de Astano revela un momento especialmente significativo y fecundo en la arquitectura industrial gallega, un conjunto de obras emblemáticas en gran medida desconocidas que se han convertido en parte fundamental de nuestro patrimonio construido.

\section{Notas}

1. Vid. Antonio S. Río Vázquez, La recuperación de la modernidad en la arquitectura gallega. Tesis doctoral (A Coruña: Universidade da Coruña, 2013). 2. Sobre Gónzález-Llanos, vid. Ramón Blecua Fraga, "El Contralmirante Honorario e Ingeniero Naval José Ma González-Llanos», Revista General de Marina 245 (2003): 243-248.

3. José Manuel Serantes Cainzos, Astano: Un estaleiro unha vivencia (Fene: Concello de Fene, 2011), 9.

4. Vid. Gillian Darley, La fábrica como arquitectura. Facetas de la construcción industrial (Barcelona: Reverté, 2003).

5. Astano. Proyecto de taller de maquinaria, Memoria (1954), 2-5. Archivo Navantia, Ferrol.

6. La documentación aportada llega a explicar la secuencia de montaje de las cerchas a través de esquemas gráficos. Alternativas, tiempos de ejecución, fases y costes son analizados a un nivel de detalle todavía inexistente en los proyectos de arquitectura visados a comienzos de los ańos cincuenta.

7. Reyner Banham. La Atlántida de hormigón (Madrid: Nerea, 1989), 18.

8. Le Corbusier, Vers une architecture (París: Crés, 1924), 28.

9. Agradezco expresamente la colaboración de Navantia en Ferrol por la custodia y cesión de los documentos de proyecto e imágenes de archivo pertenecientes al fondo de Astano.

\section{Procedencia de las Imágenes}

Todas las imágenes proceden del Archivo Navantia Ferrol (Fondo Astano)

\section{Sobre el autor}

Arquitecto por la E.T.S.A. de A Coruña, Master en Urbanismo y doctor por la Universidade da Coruña. Profesor en el Departamento de Composición de la Universidade da Coruńa impartiendo docencia en las asignaturas Introducción a la Arquitectura, Expresión Artística, Paisaje Cultural e Historia de la Arquitectura. Profesor invitado en la Robert Gordon University de Aberdeen (Reino Unido). Director del proyecto de investigación «Historia de la restauración y puesta en valor del patrimonio arquitectónico en Galicia», becado por la Diputación Provincial de A Coruña en la Convocatoria de Becas de Investigación del año 2007. Autor del libro Las Universidades Laborales gallegas. Arquitectura y modernidad (Colegio Oficial de Arquitectos de Galicia, 2011). Los resultados de sus investigaciones, tanto personales como conjuntas, han servido como aportación a varios seminarios, jornadas, congresos y eventos de difusión científica nacionales e internacionales y han sido publicados en libros, revistas y actas de congresos.

ario@udc.es 